\title{
ABORDAGEM SISTÊMICA PARA SOLUÇÃO DE PROJETOS COMPLEXOS: IMPLANTAÇÃO DE UM ERP EM UMA MINERADORA
}

\author{
${ }^{* 1}$ Nathan Peixoto Oliveira, ${ }^{2}$ Bruno Reis Leite, ${ }^{3}$ Rômulo Henrique Gomes de Jesus, ${ }^{4}$ Danielle \\ Gonçalves de Oliveira Prado \\ ${ }^{1,2}$ Université de Bordeaux, 33000, Bordéus-AQ, França \\ ${ }^{3}$ Universidade Tecnológica Federal do Paraná, 84016-210, Ponta Grossa-PR, Brasil \\ ${ }^{4}$ Universidade Tecnológica Federal do Paraná, 86812-460, Apucarana- PR, Brasil \\ *nathanpeixot@yahoo.com.br
}

\begin{abstract}
RESUMO
A efetividade do projeto está diretamente relacionada com suas diretrizes iniciais e a fase de planejamento, sendo fundamentais para o sucesso do projeto. O grande desafio é definir soluções viáveis e sustentáveis, visto que a complexidade dos cenários atualmente exige análises bem elaboradas para avaliação de riscos e possíveis impactos nos stakeholders. Deste modo, as abordagens sistêmicas vêm auxiliar, especialmente sobre as variáveis qualitativas do cenário, analisando a influência das partes envolvidas, ponderando seus diferentes objetivos e considerando os efeitos colaterais das ações, se mostrando uma ferramenta relevante para o gestor de projetos. Este trabalho tem como objetivo utilizar este modelo para intervenção em projetos complexos, onde, através de um estudo de caso, contemplou-se um projeto de implantação de um ERP em uma mineradora. O artigo apresentou uma solução efetiva sob diferentes perspectivas, considerando as diferentes partes interessadas envolvidas e auxiliando a comunidade acadêmica com um método padronizado e simplista para tomada de decisões em ambientes complexos.
\end{abstract}

Palavras-chave: Gerenciamento de Projetos; Pensamento Sistêmico; Problemas Complexos.

\section{SYSTEMIC APPROACH TO COMPLEX PROJECT SOLUTION: IMPLEMENTATION OF AN ERP IN A MINING COMPANY}

\begin{abstract}
The Project effectiveness is directly related to its initial guidelines and the planning phase, being fundamental to the success of the project. The big challenge is to define viable and sustainable solutions, as the complexity of the scenarios currently requires well-designed analyzes to assess risks and possible impacts on stakeholders. Thus, the systemic approaches help, especially on the qualitative variables of the scenario, analyzing the influence of the parties involved, weighing their different objectives and considering the side effects of the actions, proving to be a relevant tool for the project manager. This work aims to use this model for intervention in complex projects, where, through a case study, a project to implement an ERP in a mining company was contemplated. The paper presented an effective solution from different perspectives, considering the different stakeholders involved and assisting the academic community with a standardized and simplistic method for decision making in complex environments.
\end{abstract}


Keywords: Project Management; Systemic Thinking; Complex Problems.

\section{Como Citar:}

OLIVEIRA, Nathan Peixoto et al. Abordagem sistêmica para solução de projetos complexos: implantação de um ERP em uma mineradora. In: SIMPÓSIO DE PESQUISA OPERACIONAL E LOGÍSTICA DA MARINHA, 19., 2019, Rio de Janeiro, RJ. Anais [...]. Rio de Janeiro: Centro de Análises de Sistemas Navais, 2019.

\section{INTRODUÇÃO}

\subsection{Apresentação do Tema}

A efetividade do projeto está diretamente relacionada com as diretrizes iniciais. A fase de planejamento é fundamental para o sucesso do projeto, e dentre suas etapas mais importantes, destaca-se a Definição do Escopo. O grande desafio desta fase é definir soluções viáveis e sustentáveis, visto que a complexidade dos cenários atualmente exige análises bem elaboradas para avaliação de riscos e impactos nas partes envolvidas.

A complexidade do cenário para muitas empresas se deve à necessidade da análise de complexas relações de poder entre as partes interessadas, seus objetivos nem sempre explícitos e principalmente tentar prever suas reações a determinadas variações no cenário. A dificuldade pode se concentrar na acomodação dos diversos interesses, principalmente entre os conflitantes. As análises mais utilizadas seguem um pensamento linear de "causa e efeito", que assim, não são completamente eficazes quando os elementos analisados são seres humanos, com seus mais diversos interesses e pontos de vista.

Nestes casos, as Abordagens Sistêmicas mostram-se mais adequadas, pois permitem um trabalho mais confiável, especialmente sobre as variáveis qualitativas do cenário, por exemplo, analisar a influência entre os envolvidos, ponderar seus diferentes objetivos ou considerar os efeitos colaterais das ações. Tanto sua análise sistêmica sobre as partes envolvidas quanto sua flexibilidade para abranger aspectos subjetivos ratificam as metodologias sistêmicas como ferramentas essenciais para o gestor de projetos.

\subsection{OBJETIVo}

Este trabalho tem como objetivo demonstrar as vantagens diferenciadas que as abordagens sistêmicas podem agregar para o planejamento de um projeto, especificamente a definição do escopo. Ao utilizá-las como ferramentas de análise em conjunto com as boas práticas sugeridas pelo PMI (2013), o Gestor de Projeto se capacita a desenvolver uma visão holística sobre o cenário, podendo assim desenvolver soluções efetivas para o problema. Serão propostos um Plano de Gerenciamento do Escopo e um Plano de Gerenciamento de Partes Interessadas, encontrados no apêndice do trabalho.

\subsection{JUSTIFICATIVA}

A Definição do Escopo lida com variáveis estratégicas complexas e subjetivas, diferentemente, por exemplo, da Gestão de Custos, Tempo ou Aquisições do Projeto. Com isso, a perspectiva de análise encontrada no Pensamento Sistêmico mostra-se muito aplicável à esta área de conhecimento. A abordagem sistêmica oferece uma análise diferenciada e complementar para a técnica de Definição do Escopo, sugerida pelo PMI (2013).

\subsection{Metodologia}

A metodologia empregada foi inspirada no trabalho de Williams e Hof (2016). Este 
livro orienta o leitor a aplicar diversos passos, baseados em metodologias sistêmicas, para a definição de uma intervenção para Problemas Complexos.

Inspirado pelos benefícios oferecidos por várias abordagens criadas em diferentes épocas do Pensamento Sistêmico, os passos envolvem a análise das relações entre os envolvidos, influências, conflitos e alianças, objetivos, poder, limites para análise, acomodação de perspectivas, entre outras questões que não são normalmente analisadas pelos gestores tradicionais, por isso a importância desta metodologia como complemento às boas práticas.

A metodologia será aplicada no estudo de caso, onde uma empresa encontra-se em um cenário complexo e necessita definir um escopo de ação. Primeiro, as ferramentas sugeridas pelo PMI (2013) para Identificação de Partes Interessadas, Coleta de Requisitos e Definição de Escopo serão analisadas para identificação de oportunidades de complemento pelas Abordagens Sistêmicas. Em seguida, a metodologia será aplicada em conjunto com as boas práticas analisadas, com a intenção de demonstrar a complementaridade que as abordagens sistêmicas podem oferecer, analisando os incrementos segundo o Pensamento Sistêmico.

\section{FUNDAMENTAÇÃO TEÓRICA}

\subsection{A ABORDAGEM SistÊMiCA}

Quando comparado com as definições de hoje, percebe-se que Churchman (1972) foi bastante assertivo sobre a abordagem sistêmica ao defini-la como a necessidade de análise dos cenários por diferentes perspectivas, ou pela interpretação do mundo pelos olhos de outrem. É a capacidade de perceber o todo integrado, como as partes se relacionam, detectar padrões e inter-relacionamentos e aprender a reestrutura-los de forma mais harmoniosa. É possível, então, enxergar através da complexidade para entender situações, suas causas e consequências.

Desde o século 20, quando Bertalanffy (1975) publicou seus primeiros trabalhos sobre a teoria dos sistemas, foi desenvolvida uma grande diversidade de abordagens sistêmicas, muitas das quais para lidar com o desafio do desenvolvimento de uma compreensão mais holística da realidade. O Pensamento Sistêmico no fim do século 20 assumiu mais o desafio de lidar com múltiplas perspectivas sobre a realidade, e o desafio ético e político de enfrentar as relações de poder associadas a diferentes realidades. Estes constituem o que tem sido chamado de abordagens sistêmicas "flexíveis" (soft) e "críticas", respectivamente (JACKSON, 2000).

Segundo Senge (2003), o pensamento sistêmico favorece aos gerentes enxergar o projeto como um todo, capaz de influenciar e ser influenciado por diversas outras variáveis internas e externas a ele. Ou seja, deixa de acreditar que um projeto é composto por áreas gerenciáveis de forma independente e passa a buscar a integração entre todas as partes compreendendo as consequências positivas e negativas das decisões e ações executadas.

Segundo Bider et al. (2011), o pensamento sistêmico se faz por três conceitos:

a) O conceito da inter-relação: sobre como as partes se ligam e suas consequências. O conceito de inter-relações abrange aspectos dinâmicos, da natureza não linear, do "emaranhado", do contexto das estruturas de relacionamento, dos processos e dos padrões; Conceito desenvolvido nas primeiras abordagens sistêmicas, definidas como Rígidas (Hard).

b) O conceito das perspectivas: olhar os cenários por diferentes aspectos e usando diferentes conjuntos de suposições dos stakeholders, valores e visões de mundo; Conceito desenvolvido nas abordagens sistêmicas definidas como Flexíveis (Soft).

c) O conceito dos limites: não é possível pensar em tudo, logo, deve-se colocar 
limites. Abordagem de questões práticas e éticas de onde e como está vinculado o foco de investigação. Conceito reforçado nas abordagens sistêmicas mais recentes, definidas como Críticas (Critical).

\subsubsection{Abordagens Rígidas}

Desde os primeiros estudos até o final dos anos 1960, o foco da área de sistemas foi sobre as inter-relações. Este período representou a fase de "esquema de ligações" e ainda é influente até hoje. De fato, algumas das abordagens de mapeamento, como mapas de rede e mapas de conceito foram assim originadas. Outros campos foram desenvolvidos neste período como a Engenharia de Sistemas, Análise de Sistemas e Pesquisa Operacional, e sobretudo, para o pensamento sistêmico, tem-se a Dinâmica de Sistemas, desenvolvida por Jay Forrester (1961), e o Modelo de Sistema Viável, desenvolvido por Stafford Beer (1972).

Segundo Reynolds (2011) a Dinâmica de Sistemas é de 1950 por Jay Forrester. É uma abordagem para a compreensão do comportamento de sistemas complexos ao longo do tempo. Trata-se de loops de feedback internos e atrasos que afetam o comportamento de todo o sistema. O que torna o uso de dinâmica de sistemas diferentes de outras abordagens para estudar sistemas complexos é o uso de loops de feedback, estoques e fluxos em exibição da não-linearidade.

Segundo Williams e Hof (2016), a Dinâmica de Sistemas é uma abordagem que procura explorar as consequências de relações não-lineares e atraso. Naturalmente, o homem enxerga as relações de causa e efeito de forma sequencial e linear: "A leva a B que leva a C”. Conforme ilustrado na figura 1: a formação (A) leva ao aumento do conhecimento (B) o que leva a um emprego em uma determinada especialização $(C)$.

A dinâmica reconhece a "não linearidade" onde, por exemplo, A e B podem alimentar-se uns aos outros e que $C$ pode causar uma redução do ciclo, conforme ilustrado na figura 1. Por exemplo: O treinamento (A) pode aumentar o conhecimento (B), e este conhecimento pode aumentar a demanda para a formação contínua (A), o que leva a um maior conhecimento (B). Ou, alternativamente, o conhecimento (B) pode levar as pessoas a conseguir emprego no campo (C), o que pode reduzir a sua capacidade de se envolver na formação contínua (A) que eles precisam, porque eles agora estão ocupados para aplicar seus conhecimentos.

Figura 1 Exemplo de comportamento linear e recursivo.

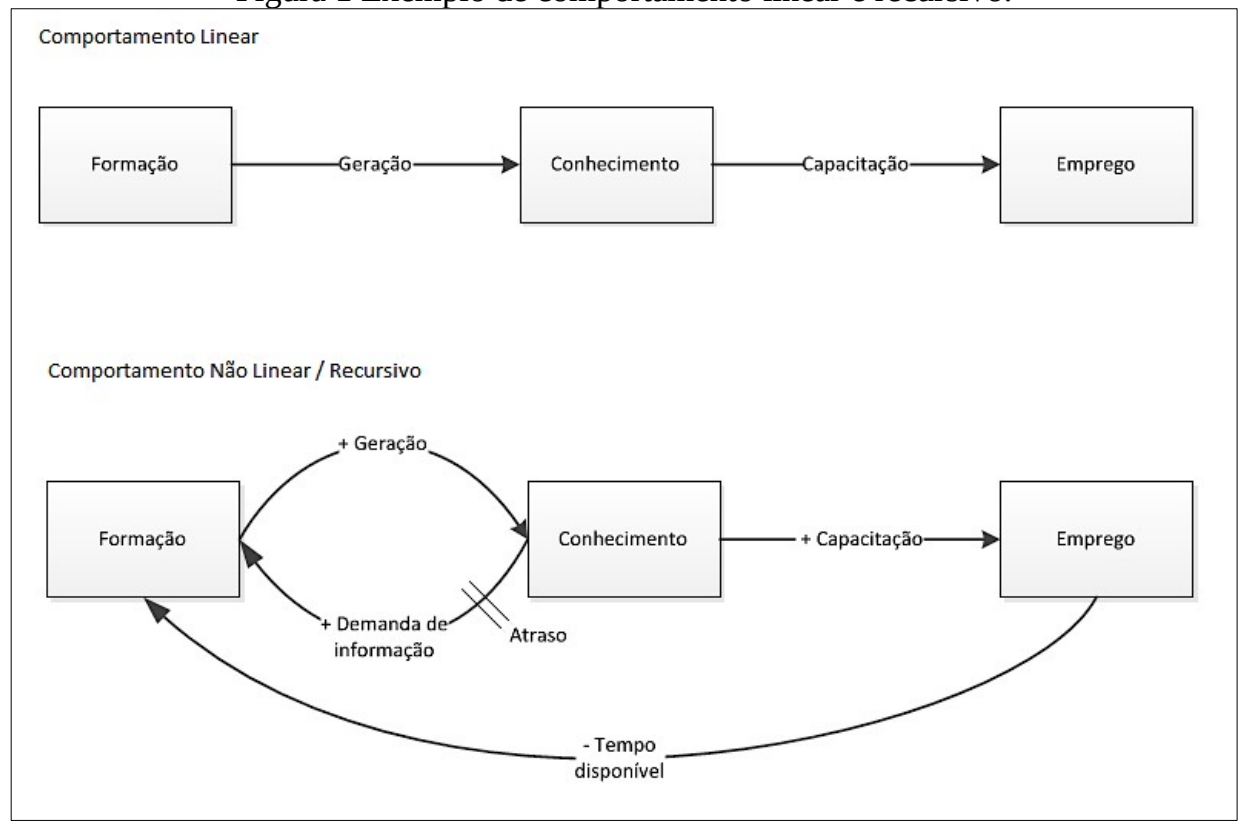

Fonte: Autor 
Em cima deste comportamento recursivo, podem haver atrasos entre "causa" e "efeito" que complicam ainda mais a imagem. Assim, embora o treinamento possa afetar o conhecimento rapidamente, o conhecimento pode afetar a demanda para a formação contínua de forma mais lenta do que ganhar o emprego afeta a demanda de mais treinamento. Assim, enquanto a capacidade da situação pode ser melhorada - pelo menos inicialmente (isto é, mais treinamento, conhecimento, emprego), ao longo do tempo a capacidade da situação reduz.

Segundo Williams e Hof (2016) o Pensamento Sistêmico preocupa-se com aspectos específicos das inter-relações, como:

a) Dinâmica: Como as inter-relações afetam o comportamento de uma situação ao longo de um período de tempo

b) Não-linearidade: Como o tamanho da saída ou efeito de inter-relações parece não estar relacionada com o tamanho da entrada para a inter-relação. Isso é muitas vezes, mas nem sempre causada por feedback. O exemplo mais simples de relacionamentos não-lineares é padrão de crescimento exponencial familiar em ecologia.

c) Sensibilidade Contextual: Como as mesmas inter-relações em diferentes contextos têm resultados diferentes. Métodos de controle da malária que funcionam bem na Tailândia pode não funcionar nas Filipinas.

d) Complexidade: Como entender as inter-relações que são tão complicadas ou complexas que não é possível avaliá-las em termos de causa e efeito.

Rosenhead (1989) define abordagem rígida como um pensamento sistemático ordenado preocupado com a definição de meios, em problemas estruturados, nos quais podem ser estabelecidos os fins desejados. Assim, para as abordagens hard não há dúvida quanto à estrutura de um problema. Essa forma de pensamento é fortemente influenciada pelo tipo de racionalidade técnica, natural a engenheiros de projeto (CHECKLAND, 1981).

Segundo Jackson (1991) uma consequência dessa perspectiva mecanicista, é o domínio de aplicação restrito das abordagens rígidas, por requererem situações claramente definidas no início da aplicação. Todavia, nas organizações, são comuns situações em que o fim a ser alcançado é, muitas vezes, a parte principal do problema. Assim, as abordagens hard não se adequam a buscar acordos em pontos de vista distintos sobre a definição de um objetivo.

Para superar tais dificuldades, proponentes das abordagens hard acabam distorcendo a natureza da situação às regras e procedimentos das metodologias. Pela necessidade de quantificação e otimização, qualquer modelo sistêmico quantitativo complexo, é sempre um processo altamente seletivo. Assim, embora otimizável, pode desconsiderar vários fatores ou não reconhecer fatores latentes em razão daqueles selecionados para integrar o modelo.

\subsubsection{Abordagens Flexíveis}

No início da década de 1970, muitos pesquisadores no campo de sistemas perceberam que a importância relativa a determinadas inter-relações, muitas vezes dependia das diferentes perspectivas através das quais as pessoas observavam a situação.

A Metodologia dos Sistemas Flexíveis (Soft Systems Methodology, SSM) faz desde o princípio o usuário considerar perspectivas alternativas. Em seguida, ela faz uma série de perguntas que ajudam a descobrir qual é a estrutura, função e as consequências lógicas de cada perspectiva. Em geral, a "realidade" é uma mistura de perspectivas.

Segundo Reynolds (2011) o principal uso do SSM é na análise de situações complexas onde há pontos de vista divergentes sobre a definição do problema. Nelas, até mesmo o problema a ser abordado pode não ser fácil concordar. A abordagem de sistemas flexíveis usa a noção de um "sistema" como um instrumento de aprendizado e interrogativa que permitirá o debate entre as partes interessadas. A metodologia é vista na literatura em duas versões: o modelo de sete atividades, modelo original proposto Checkland (1981) e o de 
quatro atividades.

O modelo de quatro atividades foi apresentado em seguida por Checkland e Scholes (1990), fazendo algumas ressalvas quanto ao primeiro modelo, por exemplo, realizar reflexões políticas e culturais sobre a intervenção, mas mantendo suas principais atividades. Algumas adaptações também foram feitas, por exemplo, o desenvolvimento da Figura Rica (Rich Picture) deixou de ser uma atividade única, para ser uma ferramenta de suporte usada em paralelo às atividades e atualizada constantemente (CHECKLAND, 2000).

O quadro 1 apresenta uma comparação entre as etapas dos dois modelos, mostrando a redução do número de etapas, porém mantendo a equivalência de pontos importantes.

Quadro 1: Comparação SSM de Checkland em 1981 e 1990

\begin{tabular}{|c|c|}
\hline Sete etapas & Quatro etapas \\
\hline 1. Identificação da situação-problema & $\begin{array}{l}\text { 1. Apurar a uma situação-problema, incluindo aspectos } \\
\text { culturais e políticos }\end{array}$ \\
\hline \multicolumn{2}{|l|}{ 2. Estruturação do cenário (Rich Picture) } \\
\hline $\begin{array}{l}\text { 3. Formular definições raízes dos sistemas relevantes } \\
\text { de atividade proposital (CATWOE) }\end{array}$ & $\begin{array}{l}\text { 2. Formulação de a partir das definições, modelos } \\
\text { relevantes de atividades intencionadas; }\end{array}$ \\
\hline \multicolumn{2}{|l|}{$\begin{array}{l}\text { 4. Construir modelos conceituais dos sistemas } \\
\text { identificados nas definições raízes }\end{array}$} \\
\hline $\begin{array}{l}\text { 5. Comparar os modelos com situações do mundo } \\
\text { real }\end{array}$ & $\begin{array}{l}\text { 3. Contrastar os modelos com as percepções do mundo } \\
\text { real considerando: Soluções desejáveis e culturalmente } \\
\text { viáveis; e a acomodação entre interesses conflitantes. }\end{array}$ \\
\hline \multicolumn{2}{|c|}{$\begin{array}{l}\text { 6. Definir as possíveis mudanças que são possíveis e } \\
\text { desejáveis }\end{array}$} \\
\hline $\begin{array}{l}\text { 7. Tomar medidas para melhorar a situação do } \\
\text { problema }\end{array}$ & 4. Agir I \\
\hline
\end{tabular}

Fonte: Adaptado de Checkland (1981) e Checkland e Scholes (1990)

\subsubsection{Abordagens Críticas}

Em meados de 1980, alguns pesquisadores viram na orientação por perspectivas alguns problemas. Elas influenciam o que é considerado relevante; determinam o que é "dentro" do enquadramento de uma situação (o modo como é entendida a situação) e que está "fora". Quem define a dominância controla o limite de uma intervenção sistêmica. Assim achou-se importante estudar limites e criticar decisões de fronteira (incluindo aqueles que os fizeram):

a) Conceito de CST: O Pensamento Sistêmico Crítico (Critical System Thinking, CST) é considerado como uma abordagem sistêmica para a investigação e intervenção em situações complexas. A abordagem foi desenvolvida pelas constatações realizadas inicialmente por C. West Churchman e seu aluno Werner Ulrich. Mais tarde, Flood e Jackson (1991) desenvolveram suas interpretações do trabalho anterior. Flood e Jackson estavam preocupados que os métodos de sistemas existentes, incluindo SSM de Checkland e outras abordagens "soft", reforçavam, ao invés de desafiar as relações de poder (FLOOD; JACKSON, 1991).

O CST se desenvolveu e tornou-se uma prática através das contribuições de Werner Ulrich. Sua motivação transparecer os planos desenvolvidos por especialistas de não levar em conta populações locais e suas necessidades. CST é, portanto, um debate em torno de três temas.

O primeiro, consciência crítica, é um processo que envolve análise de fronteira, considerando de maneira formalizada onde e por quem julgamentos de fronteira são feitos. W Examinando suposições "certas" e as condições que deram origem a elas (MIDGLEY et at., 1988; MIDGLEY, 1996). A motivação é para tratar de questões de marginalização.

Já o segundo, melhoria (ou emancipação, desenvolvimento ou mudança desejada), é 
definida temporariamente e localmente, levando em conta questões de poder. E por fim, o pluralismo metodológico, usa uma variedade métodos flexíveis, dinâmicos e localmente determináveis. O objetivo é trabalhar com partes interessadas locais e facilitar a sua capacidade de selecionar e utilizar métodos mais relevantes, levando em conta questões de poder.

b) Conceito de CSH: A Heurística Sistêmica Crítica foi desenvolvida por Werner Ulrich (1994, 2002) como forma de reflexão e debate. Ela permite identificar conflito de interesses e promove a emancipação dos afetados pelas premissas dos projetistas.

A Heurística Sistêmica Crítica introduz conceitos críticos no processo de planejamento, como, por exemplo, a necessidade de confrontar a posição técnica dos planejadores e projetistas com a posição dos grupos sociais que serão afetados direta ou indiretamente com a implantação do projeto. Para suportar um processo sistemático de crítica de fronteira, a CSH introduz doze categorias de mapeamento pragmático e, correspondentemente, doze perguntas críticas de fronteira no modo "é” e doze perguntas no modo "deveria”.

Jackson (1991) explica que há quatro grupos de questões que se referem respectivamente ao cliente, aos responsáveis pelas decisões, aos planejadores e aos cidadãos afetados pelas decisões. As questões relacionadas ao cliente interrogam sobre a fonte de motivação que flui pelo projeto em questão. As relacionadas aos responsáveis pelas decisões, sobre a fonte de controle construído dentro do projeto. As relacionadas aos planejadores, sobre a fonte das habilidades e conhecimentos assumidos como adequados para o projeto. As relacionadas ao último grupo, acerca da fonte de legitimação do projeto.

Existem três questões em cada grupo, relacionada cada uma, a uma das categorias. A primeira pergunta diz respeito à categoria "papel social” dos envolvidos ou afetados pelo projeto, a segunda se refere ao "papel da preocupação específica” no projeto e a terceira ao "problema chave" ou questão crucial que determina os julgamentos de fronteira acerca das duas primeiras categorias. O modelo com as questões está ilustrado no quadro 2.

Quadro 2: Categorias e Questões de Fronteira (CSH)

\begin{tabular}{|c|c|c|c|}
\hline \multirow[b]{2}{*}{ Fonte de Influência } & \multicolumn{3}{|c|}{ CSH - Categorias e Questões de Fronteira } \\
\hline & $\begin{array}{l}\text { Papéis sociais } \\
\text { (Stakeholders) }\end{array}$ & Interesses especificos & Problema chave \\
\hline \multirow[b]{2}{*}{ Motivação } & Beneficiário & Propósito & Medida de melhoria \\
\hline & $\begin{array}{l}\text { Quem é/deveria ser visto como } \\
\text { cliente/beneficiário de } S ?\end{array}$ & $\begin{array}{l}\text { Qual é/deveria ser o propósito de } \\
\text { S? }\end{array}$ & $\begin{array}{l}\text { Qual é/deveria ser a medida de } \\
\quad \text { melhoria utilizada? }\end{array}$ \\
\hline \multirow[b]{2}{*}{ Controle } & Decisores & Recursos & Ambiente de decisão \\
\hline & $\begin{array}{l}\text { Quem está/deveria estar no } \\
\text { controle de } S ?\end{array}$ & $\begin{array}{l}\text { Quais recursos estão/deveriam } \\
\text { estar no controle do decisor? }\end{array}$ & $\begin{array}{l}\text { Quais condições de sucesso } \\
\text { estão/deveriam estar sob controle } \\
\text { de terceiros? }\end{array}$ \\
\hline \multirow[b]{2}{*}{ Conhecimento } & Especialista & Especialidades & Garantidor \\
\hline & $\begin{array}{c}\text { Quem está/deveria estar } \\
\text { contrbuindo com sua experiência } \\
\text { e conhecimento? }\end{array}$ & $\begin{array}{c}\text { Qual tipo de conhecimento } \\
\text { é/deveria ser consultado? }\end{array}$ & $\begin{array}{l}\text { O que é/deveria ser considerado } \\
\text { como garantia da implementação } \\
\text { bem sucedida? }\end{array}$ \\
\hline \multirow[b]{2}{*}{ Legitimidade } & Testemunhas & Emancipação & Visão de mundo \\
\hline & $\begin{array}{l}\text { Quem está/deveria estar } \\
\text { representando as preocupações } \\
\text { das partes afetadas por S? }\end{array}$ & $\begin{array}{c}\text { Quais são/ deveriam ser as } \\
\text { oportunidades para as partes } \\
\text { afetadas negativamente de se } \\
\text { emanciparem de } S \text { e terem }\end{array}$ & $\begin{array}{l}\text { Qual visão de mundo as partes } \\
\text { interessadas se } \\
\text { baseam/deveriam se basear? }\end{array}$ \\
\hline
\end{tabular}

Fonte: Adaptado de Ulrich e Reynolds (2010) 


\subsection{Problemas Complexos em Projetos}

Um Um Problema Complexo é um problema difícil ou impossível de resolver porque apresenta exigências incompletas, contraditórias e inconstantes, que muitas vezes são difíceis de reconhecer. Além disso, por causa de complexas interdependências, o esforço para resolver um aspecto de um Problema Complexo pode revelar ou criar outros problemas.

Rittel e Webber (1973) argumentam que os problemas sociais, tais como os enfrentados pelo planejamento, não são como os problemas relacionados à engenharia, matemática ou mesmo às ciências naturais e, portanto, não podem ser solucionados com os mesmos métodos. Segundo eles, os problemas enfrentados pelo planejamento podem ser considerados "Complexos" (wicked, no original). Na solução de uma equação, ou numa partida de xadrez, sabe-se de antemão todas as condições do problema, as regras para sua resolução e os critérios necessários para saber se a solução foi correta, ou mesmo se pode ser ou não considerada uma solução. Nos Problemas Complexos isso não se aplica

Seu sentido foi apresentado em 1967 por Charles W. Churchman em um editorial na revista Management Science, em resposta a uma utilização do termo por Horst Rittel anteriormente. Churchman (1972) discutiu a responsabilidade moral da Pesquisa Operacional em informar aos usuários em quais aspectos as suas "soluções" não conseguiriam domar seus Problemas Complexos. Rittel e Webber (1973) esclarecem em seu artigo o sentido do adjetivo wicked: similiar ao de "maligno" (em contraste a "benigno") ou vicioso (como um círculo) ou "traiçoeiro" (como um duende) ou "agressivo" (como um leão, em contraste com um cordeiro).

Segundo Midgley (2015) Problemas Complexos envolvem:

a) Muitas questões interligadas, atravessando diferentes campos como economia, saúde e meio ambiente, proporcionando um alto grau de complexidade;

b) Diferentes setores como público, privado e terceiro setor, tentando dar conta de múltiplas escalas (local, regional, nacional e global);

c) Muitas opiniões diferentes sobre o problema e as possíveis soluções;

d) Conflito sobre os resultados desejados ou os meios para alcançá-los, e as relações de poder que fazem a mudança difícil; e

e) A incerteza sobre os possíveis efeitos da ação.

Rittel e Webber (1973), enfatizam que os ambientes sociais são interligados a sistemas abertos e a grandes redes de sistemas, onde saídas de um sistema podem se tornar entradas para outros, dificultando identificar onde está o problema central e onde se deve intervir. Estas redes interligadas de sistemas sociais produzem "ondas de repercussões geradas por uma ação de resolução de problemas direcionada para qualquer um dos nós da rede e não há surpresa em encontrá-las induzindo problemas de maior gravidade em algum outro nó desta rede”. (RITTEL; WEBBER, 1973, p. 159).

De acordo com as descrições de Rittel e Webber (1973), os problemas encontrados no desenvolvimento de um projeto, desde seu planejamento até o encerramento, podem ser considerados Problemas Complexos. Pela natureza subjetiva dos problemas, conflitos humanos, nem sempre há solução simples e viável de ser aplicada, e muitas vezes uma trégua entre partes conflitantes já é uma conquista importante.

Durante Análise de partes interessadas, o Gestor necessita reconhecer a influência entre as partes, os conflitos e parcerias de interesses, e as relações de poder e políticas. Durante a coleta de requisitos, o é necessário enfrentar tarefas "como conseguir entender os objetivos reais por trás dos requisitos" que envolve o enorme risco de interpretações precipitadas, assim como lidar eventualmente com partes interessadas que não queiram colaborar com o projeto por motivos desconhecidos para o gerente. Já na definição do escopo, decisões como “definir quais requisitos não serão atendidos” envolvem altos riscos de geração 
de conflitos com as partes que se sintam prejudicadas ou ignoradas, e que potencialmente possam dificultar o desenvolvimento do projeto. Em nenhuma dessas situações o Gestor pode se sentar e anotar exatamente suas preocupações ou os objetivos e, depois, discutir como esses objetivos poderão ser alcançados.

Williams e Hof (2016) fizeram uso das abordagens sistêmicas para a intervenção em Problemas Complexos. O objetivo da metodologia é capacitar o usuário a extrair e analisar as informações necessárias para a tomada de decisão correta para plano de ação, fornecendo uma diretriz em meio à complexidade da situação inicial. A utilização de ferramentas sistêmicas permite uma abordagem diferenciada para o cenário caótico, resultando em uma visão tão abrangente quanto as perspectivas dos envolvidos, assim como definida sobre as prioridades após as críticas de fronteira. As 10 etapas sugeridas na metodologia são influenciadas por diferentes abordagens sistêmicas.

i) Análise de Inter-relações: o mapeamento do Problema Complexo:

1. Identificação do problema, definindo a natureza da intervenção sistêmica e

2. Desenho da Figura Rica, abrangendo tudo o que possa ser relevante;

ii) Análise de Perspectivas:

3. Análise das partes interessadas, para determinar quem são os mais interessados;

4. Identificação dos interesses, para identificar quais são as principais preocupações dos envolvidos e

5. Formulação dos pontos de vista: para "ver através dos olhos do outro".

iii) Análise de Fronteiras:

6. Análise da Figura Rica: resumo das ideias-chave da figura rica;

7. Esboço da situação ideal: Objetivos são motivados por ideais e

8. Crítica de fronteira: Questionário sistêmico nas escolhas de fronteira que definem a razão do "cenário atual” e como alcançar o "cenário desejado".

iv) Desenvolvendo Intervenção:

9. Projetar a Intervenção Sistêmica: Finalizar o projeto de intervenção para melhorar a sua viabilidade geral, fazendo uso dos conhecimentos adquiridos a partir da crítica de fronteira.

v) Verificação final:

10. Verificação final: Repetir as etapas quando necessário. A abordagem sistêmica é sempre incompleta.

Uma vez que seja implementada a intervenção, o praticante deverá garantir que se manterá ágil para redesenhar quando necessário. A abordagem sistêmica, é sempre incompleta. Ação cria mais informações mais ideias e perspectivas. Caso necessário, não é essencial para passar por todo o processo sugerido cada vez que for mudar o seu desenho, mas é importante ter atenção quanto: a atualização da imagem rica; atualização das perspectivas; e questões de fronteira.

\section{ESTUDO DE CASO}

Conforme descrito na fundamentação teórica, Williams e Hof (2016) fizeram uso das abordagens sistêmicas para a intervenção em Problemas Complexos. A proposta deste trabalho é relacionar a metodologia apresentada por Williams e Hof (2016) com as ferramentas sugeridas pelo PMI (2013), ilustrando o trabalho complementar que as Abordagens Sistêmicas podem oferecer em conjunto com as boas práticas da Gestão de Projeto. As etapas da metodologia são correlacionadas às ferramentas sugeridas pelas boas práticas de Gestão de Projetos, entretanto apresentam as qualidades diferenciais das abordagens sistêmicas, conforme analisado abaixo:

1. Identificação do problema e 
2. Identificação do problema;

Para a identificação inicial do problema, a metodologia não indica uma ferramenta específica para esta etapa, deixando livre para a escolha do usuário. Para tanto, a etapa pode ser relacionada ao processo de (4.1) "Desenvolver o termo de abertura do projeto", suas entradas aos documentos (4.1.1.1) Especificação do trabalho do projeto e (2.1.5) Fatores ambientais da empresa, e seus resultados ao (4.1.3.1) Termo de abertura do projeto. Sendo assim, o usuário pode seguir esta boa prática, caso veja necessidade.

A análise das inter-relações, "Elaborar Figura Rica", possui o importante papel de identificar as inter-relações ao mesmo tempo em que aborda diferentes perspectivas. Esta etapa mescla boas práticas como (13.1) Identificar as partes interessadas e (5.2) Coletar Requisitos, ferramentas como (13.1.2.1) Análise de partes interessadas, (5.2.2.2) Grupos de discussão; (5.2.2.3) Oficinas facilitadas; (5.2.2.4) Técnicas de criatividade em grupo; (5.2.2.10) Diagramas de contexto; e documentos sugeridos pelo PMI (2013) e conhecimentos do apêndice (X3.7) Conhecimento político e cultural.

A Figura Rica possui um diferencial em relação às boas práticas, citado anteriormente, de incluir diferentes perspectivas em uma mesma imagem. Com isto, oferece uma visão mais fidedigna sobre a situação, oferecendo ao usuário a oportunidade de avaliar variáveis subjetivas, como objetivos implícitos aos requisitos, e até especular reações dos envolvidos para as ações propostas, possibilitando o desenvolvimento de estratégias mais efetivas. Todas as dimensões sistêmicas descritas por Cabrera e Cabrera (2015) são analisadas nesta etapa, sendo que a "Perspectiva” somente é possível devido ao uso da Figura Rica.

3. Análise das Partes Interessadas;

4. Identificação dos interesses e

5. Formulação dos pontos de vista.

A Análise das Partes Interessadas é muito semelhante ao processo sugerido pelo PMI (2013) (13.1) Identificar as Partes Interessadas, mais exatamente à ferramenta (13.1.2.1) Análise de partes interessadas, tal como seu produto, o documento (13.1.3.1) Registro das partes interessadas. Porém, a maioria das análises deste processo já foram ilustradas na Figura Rica, de forma dinâmica e integrada.

A metodologia sugere a utilização de uma tabela, relacionando o stakeholder, como este impacta, como ele é impactado e a importância deste na situação. Um diferencial oferecido pelas abordagens sistêmicas é que, além de analisar o impacto dos envolvidos nos objetivos do usuário, também dá relevância ao impacto das ações do usuário nos envolvidos, que não somente envolve um caráter social de preocupação com terceiros, como elimina possíveis resistências, tentativas de boicotes e problemas futuros com potenciais prejudicados.

Em seguida está a etapa "Identificação dos interesses", que também possui um processo correspondente sugerido pelo PMI (2013), (5.2) Coletar de Requisitos, onde diversas ferramentas sugeridas são complementares à metodologia. $\mathrm{O}$ documento (5.2.3.1) Documentação dos requisitos se assemelha à entrega dessa etapa da metodologia.

De maneira similar, porém enxuta, a metodologia sugere uma lista relacionando a parte interessada e seus interesses, ponderando a importância destes para o contexto. O autor destaca a importância de listar e classificar inclusive os interesses que impactam negativamente o cenário. Apesar de mais simples, esta lista servirá de insumo para a próxima etapa.

A etapa de Formulação dos Pontos de Vista é uma atividade típica das abordagens sistêmicas modernas. A intenção é selecionar pontos de vista chaves, os quais levarão às reflexões importantes para o desenvolvimento da solução e definição do escopo.

Williams e Hof (2016) sugerem para esta etapa:

a) Listar as Partes Interessadas que exercem maior impacto sobre a situação. O 
impacto pode ser positivo ou negativo;

b) Listar os interesses que são as influências mais importantes na situação. A influência pode ser positiva ou negativa;

c) Comparar as duas listas e considerar o impacto sobre a situação. Quais problemas podem surgir desses impactos?;

d) Analisando estes problemas, refletir: "Quais são as diferentes maneiras de entender o do que se trata a situação" ou "como as pessoas entendem o que está acontecendo? ”. Uma dica é completar a frase "algo a ver com ..." e

e) Decidir quais destas perspectivas irão originar os melhores ideias que irão dar suporte ao desenvolvimento do escopo. Estas serão as perspectivas chave.

Não há processo ou ferramenta dentre as boas práticas do PMI (2013) que sugiram a reflexão sobre importância do trabalho sobre diferentes perspectivas. Deste modo, esta etapa se destaca pelo insumo diferenciado que oferece ao Gestor do Projeto.

6. Análise da Figura Rica: resumo das ideias-chave da figura rica;

7. Esboço da situação ideal: Objetivos são motivados por ideais e

8. Crítica de fronteira: Questionário sistêmico nas escolhas de fronteira que definem a razão do "cenário atual” e como alcançar o "cenário desejado".

Uma das principais abordagens do Pensamento Sistêmico, a Crítica de Fronteiras exerce um importante papel na metodologia. Começa com a “Análise da Figura Rica”, onde se resumem as ideias principais da Figura Rica. Apesar de analisar um produto da própria metodologia, se assemelha à ferramenta (5.2.2.11) Análise dos documentos, do Processo de Coleta de Requisitos, onde busca-se informações relevantes da documentação existente, neste caso, sobre o cenário em análise. Nesta etapa deve-se voltar à Figura Rica e anotar seus pontos chave, os quais serão usados mais tarde para a tomada de decisões.

A etapa da metodologia "Esboçar situação ideal” necessita de habilidades específicas do gestor, como a indicada pelo PMI (2013) (X3.8) Negociação, pela alta probabilidade de geração de conflitos. Através de ferramentas como (5.2.2.5) Técnicas de tomada de decisão em grupo, (5.3.2.3) Geração de alternativas e (5.2.2.4) Técnicas de criatividade em grupo, a equipe deve desenvolver a situação ideal para as principais perspectivas definidas nas etapas anteriores. Não se atentando ao futuro "mais provável”, mas sim ao “ideal”, cerca de 5 anos no futuro.

A “Crítica de fronteira” é a principal etapa na metodologia, correspondente à Heurística Crítica de Sistemas, uma das mais recentes vertentes do Pensamento Sistêmico, onde se questiona o propósito, recursos, conhecimentos e legitimidade da intervenção através do conflito de perspectivas. De fato, é um (5.2.2.6) Questionário, porém interno na metodologia, para debate de ideias. O produto deve guiar os limites de ação e aspectos relevantes da intervenção. As ideias oriundas deste processo serão mais aprimoradas que as originais, por passarem por questionamentos de diversas naturezas.

A prática sistêmica de reflexão periódica sobre as ideias desenvolvidas ao longo da metodologia, de diferentes formas, naturezas e perspectivas, filtra as menos ideias efetivas, sobrando apenas as mais consistentes para o desenvolvimento da melhor solução viável.

9. Projetar a Intervenção Sistêmica.

O produto da Crítica de fronteira permite iniciar o "Esboço da Intervenção Sistêmica”, semelhante ao processo (5.3) Definir o escopo. Esta etapa também gera muito debate e necessita de (5.3.2.3) Geração de alternativas e (5.3.2.4) Oficinas facilitadas. O produto almejado é a melhor intervenção viável, semelhante à (5.3.3.1) Especificação do escopo do projeto. A intervenção deve atender aos principais requisitos das diferentes partes interessadas, priorizando a acomodação destes, dentro dos limites de recursos disponíveis.

10. Verificação final. 
Por fim, a metodologia indica a etapa de "revisão final” de algumas etapas quando necessário, pois uma abordagem sistêmica é sempre incompleta e deve reaplicada em ciclos.

\section{DISCUSSÃO DO TEMA E RESULTADOS}

Intervenções desenvolvidas sistemicamente são necessárias porque a compreensão e gerenciamento convencionais não podem resolver os Problemas Complexos. Concepção sistêmica é capaz de levar em conta as inter-relações complexas e perspectivas divergentes das principais partes interessadas e utilizar esta informação em uma maneira inteligente de projetar uma intervenção eficaz por deliberar questões críticas.

i) Cenário de aplicação do modelo

O contexto do estudo de caso se passa em uma grande empresa de mineração que se encontra em uma situação de risco de grande urgência e impacto em suas operações. Onde os altos executivos optaram por trocar o seu ERP (Enterprise Resource Planning) e com isso, ao fim do projeto, foi identificada a perda de informações importantes, dentre elas, de milhares de Notas Fiscais emitidas no período de implantação. Em média, a empresa recebe cerca de 7.000 NFs por mês, dos 3.000 fornecedores com contratos ativos. Até o momento do estudo de caso, haviam cerca de 25.000 NFs em atraso (backlog), somando cifras milionárias e sem essas Notas Fiscais, a área de Contas a Pagar não poderiam efetuar os pagamentos aos fornecedores. O impacto do problema se estenderia por diversas áreas, internas e externas à empresa.

Começando pelos próprios fornecedores, é possível identificar o impacto financeiro, que pode não ser significativo em empresas grandes, mas pode ser crítico para boa parte, principalmente para os que possuem a mineradora como cliente principal.

O cenário se tornou urgente quando muitos fornecedores anunciaram interromper entregas de produtos e serviços e os menores de fechar as portas. Com isso há o impacto social relacionado, pois a mineradora possui operações em pequenas cidades que vivem essencialmente dos empregos proporcionados e da prestação de serviços para esta. Este é um requisito relevante para empresas de capital aberto. Sem entregas, as operações sentiriam o impacto na produção de minério na ordem de milhares de dólares por hora. Além da falta de opções de fornecedores nas pequenas cidades, seja pela especificidade do trabalho ou pela falta de alternativas, o que prejudicaria definitivamente suas operações.

A produção sendo prejudicada, não seria possível atender os clientes, afetando as relações comerciais e resultando em multas contratuais. Os clientes sofreriam impacto em sua cadeia produtiva pela falta de insumos, com suas consequências operacionais e financeiras, e não há medida emergencial neste caso, pois não é fácil a troca de fornecedor de minério.

Ao não receber os produtos, os clientes se recusariam a pagar a mineradora, o que impactaria diretamente na receita da empresa, prejudicando mais ainda as finanças e impossibilitando o pagamento das contas atrasadas e das despesas fixas. Assim fecha-se um "ciclo de impactos", voltando a afetar os fornecedores. Como todo ciclo, a não ser que haja uma intervenção, a tendência é aumento, neste caso, do prejuízo.

Internamente também há diversas partes interessadas como a área de Contas a Pagar que se preocupa com desorganização das notas em atraso, pelo trabalho de conciliação de cada uma com as ordens de compra correspondentes, para conferir a legitimidade das cobranças, e pela entrada de novas notas todo mês, que permaneceria constante junto com as adaptações ao novo sistema. Com isso, certamente levariam meses para quitar as notas em atraso.

A área Financeira alerta um possível rombo no caixa caso não haja cautela, em especial devido a flutuações no preço do minério e grandes investimentos feitos. A área Comercial aponta desgaste no relacionamento com clientes e fornecedores, principalmente em 
uma indústria pouco diversificada como a mineração. A área Jurídica alerta possíveis processos judiciais, e a área de Contratos, potencial prejuízo por multas proporcionais ao tempo decorrido.

Observa-se uma grande quantidade de partes envolvidas na situação, internas e externas à empresa, com diferentes interesses, importâncias e urgências, configurando um Problema Complexo, segundo Rittel e Webber (1973) e Conklin (2006). Para tanto, o Gestor do Projeto necessita utilizar uma abordagem sistêmica, alinhadas com as boas práticas sugeridas pelo PMI (2013), para o desenvolvimento de uma intervenção adequada para tentar conter o caos da situação. A abordagem aplicada no estudo de caso foi desenvolvida por Bob Williams e Sjon Van’t Hof (2016) e referenciada na fundamentação teórica. A seguir encontram-se as etapas descritas no livro e a utilização destas no caso da mineradora.

ii) Aplicação do modelo proposto

1. Identificação do Problema: Esta etapa consiste em identificar de forma geral o problema que deverá ser analisado. No caso em estudo, houveram problemas durante a implantação do ERP que ocasionaram a perda de informação sobre milhares de notas fiscais. Os fornecedores estão a 3 meses sem receber pagamento e ameaçam interromper seus serviços. A empresa não possui caixa para pagar todas as dívidas.

Com estas informações, nota-se que o problema inicial tomou grandes proporções, envolvendo diversas áreas externas à empresa, aumentando exponencialmente a complexidade da situação. Conforme sugerido pelo PMI (2013), a análise dos Ativos organizacionais, principalmente os (2.1.5) Fatores Ambientais da Empresa são de grande importância para a etapa inicial, tal como é para o processo de (4.1) "Desenvolver o termo de abertura do projeto".

2. Figura Rica: faz uso de uma das mais famosas ferramentas do Pensamento Sistêmico, sugerida por Checkland em sua Metodologia de Sistemas Flexíveis nos anos 80. O foco não é identificar o sistema, mas entender como as partes envolvidas pensam sistemicamente sobre a realidade caótica do cenário, conforme ilustrado na figura 2.

Figura 2: Figura rica 




Fonte: Autor

Conforme esclarecido previamente, a proposta da Figura Rica é semelhante à dos processos (13.1) Identificar as partes interessadas e (5.2) Coletar Requisitos. A função das ferramentas (13.1.2.1) Análise de partes interessadas e (5.2.2.10) Diagramas de contexto são incorporadas à Figura Rica, somada às análises sistêmicas. Informações encontradas no apêndice (X3.7) Conhecimento político e cultural também auxiliam no enriquecimento da Figura, que é a representação do cenário em análise e será base das análises das etapas seguintes.

A representação gráfica de tantas informações, apesar de não ser visualmente clara à primeira vista, permite uma análise simultânea de diversos fatores, possibilitando a identificação de correlações improváveis que talvez não fosse possível em análises independentes.

3. Análise das Partes Interessadas: Com a identificação das partes interessadas na Figura Rica, é necessária uma análise sobre seus papéis, impactos e vulnerabilidade no cenário em análise. Esta etapa se assemelha muito à ferramenta (13.1.2.1) Análise de Partes Interessadas, sugerida pelo PMI (2013), porém de maneira mais enxuta, pois grande parte das informações sobre os envolvidos já foi ilustrada na Figura Rica. Nesta etapa resta somente registrar:

a) "Impacta em": Refere-se à influência ou controle que o papel das partes interessadas tem sobre a situação em análise, ou a intervenção que está sendo planejada. É importante identificar se ele ajuda ou impede um ou ambos;

b) “É impactado por": Diz respeito ao impacto sentido por este papel da parte interessada, o que pode ser positivo ou negativo e interessadas.

c) "Importância": Refere-se a fatores mais amplos sobre o papel das partes

4. Identificação dos Interesses: Tal como o processo (5.2) Coletar de Requisitos, esta etapa analisa os interesses das Partes Interessadas sobre o problema em análise. Além de 
relacionar os interesses com seus respectivos “donos”, o quadro solicita uma classificação da importância deste requisito em meio ao cenário, tal como o documento (5.2.3.1) Documentação dos requisitos sugerido pelo PMI (2013).

5. Seleção da Perspectivas: Esta etapa consiste em selecionar cerca de 3 perspectivas diferentes sobre o cenário. O objetivo é que elas sejam as mais distintas dentro do possível, para que o conflito seja enriquecedor para o desenvolvimento da intervenção, uma vez que diversos valores e objetivos sejam debatidos.

a) Pagamento dos fornecedores: Perspectiva dos próprios fornecedores que querem as contas pagas, possuem urgência para evitar falência, apontam risco de desemprego nas cidades pequenas, de multas e processos, de impacto na imagem da empresa, nas arrecadações para os municípios e interrupção do fornecimento de produtos e serviços, afetando gravemente a cadeia produtiva.

b) Controle sobre pagamentos: Perspectiva de Contas a Pagar, que foi prejudicada com a perda das informações das notas fiscais dos últimos meses e precisa cadastrar o backlog, conciliar o backlog com as OCs correspondentes, lidar com o fluxo normal de entrada das NFs e aprender a manusear o novo sistema.

c) Restrições orçamentárias: Perspectiva da área Financeira que solicita ações alternativas para o pagamento das notas em atraso, pois não há dinheiro em caixa para honrar todas as dívidas, sem que isso comprometa investimentos patrimoniais importantes e outros compromissos. Uma medida extrema pode afetar outras áreas da empresa, piorando a situação crítica atual.

Esta etapa representa uma das principais ideias sistêmicas, o esforço para compreender e considerar diferentes perspectivas, no intuito de desenvolver uma solução onde haja o máximo da acomodação entre os objetivos.

6. Análise da Figura Rica: Nesta etapa, o usuário deve voltar à Figura Rica e analisar as principais relações, problemas e partes interessadas representadas. Conforme já mencionado, segue a sugestão do PMI (2013) para realizar uma (5.2.2.11) Análise dos documentos para Coleta de Requisitos. Nesta etapa, deve-se destacar e analisar o pontoschave da Figura Rica.

7. Esboço da Solução ideal: A partir das perspectivas definidas na etapa 5, deve-se idealizar o melhor cenário futuro possível. A intervenção final deverá focar nos objetivos descritos nesta etapa. As (5.2.2.4) Técnicas de Criatividade em Grupo, sugeridas pelo PMI (2013), são muito úteis nesta etapa para o desenvolvimento mais completo dos cenários.

Para os fornecedores, a situação ideal é ter seus pagamentos de forma consistentes para então poder investir e expandir seus negócios e realizar investimentos internos para melhorar a qualidade de seu produto ou serviço atualmente oferecido assim como desenvolver novos para vender para a mineradora e novos clientes. Assim gerando mais empregos em sua cidade, podendo pagar bons salários para seus funcionários e observando toda a cidade se desenvolver graças aos investimentos diretos, oportunidades oferecidas pela mineradora e arrecadações da prefeitura sendo investidos em melhorias na cidade.

Para o Contas a Pagar, a situação ideal é trabalhar com um sistema ágil e robusto, que permita um controle minucioso sobre pagamentos através da geração de relatórios precisos. Que as entradas do sistema sejam dados apurados e sejam armazenados em um banco de dados robusto e confiável. Que o sistema permita a que as tarefas sejam feitas de forma quase automática, cabendo apenas a autorização por parte de uma pessoa responsável, em tarefas como conciliação com as ordens de compra, dentre outras tarefas internas. Também que o processo esteja sempre atualizado e que não haja questionamento por parte dos fornecedores. Espera-se dos fornecedores a compreensão que, em caso de imprevistos, estes possuam flexibilidade para aguardar enquanto o problema seja resolvido. 
Para a área Financeira a empresa deve possuir uma reserva em caixa suficiente para lidar com imprevistos, sem necessariamente sacrificar outros investimentos e despesas. Espera-se também que as outras áreas também tenham como prioridade a saúde financeira da empresa, desenvolvendo estratégias que evitem o gasto desnecessário ou excessivo de recursos. Assim como as receitas sejam consistentes, como o pagamento dos clientes e investimentos de acionistas.

8. Crítica de Fronteira: Uma das principais etapas da metodologia, inspirada na abordagem Heurística de Sistemas Críticos desenvolvida por Ulrich (1983). Sobre quatro focos diferentes, nesta etapa deve-se responder as questões definidas para descrever o cenário atual e o almejado, em seguida deve haver uma crítica mútua das ideias para definir os limites da ação, priorizando objetivos e avaliando viabilidades, seguindo a metodologia de Ulrich. Trata-se de um (5.2.2.6) Questionário, conforme sugerido pelo PMI (2013), porém interno à metodologia, usado para testar as ideias desenvolvidas anteriormente e servir de molde para a solução viável.

9. Esboçar intervenção sistêmica. Por fim, deve-se analisar os pontos chaves das reflexões geradas na etapa anterior, e tentando atender ao máximo dos requisitos, desenvolver a melhor intervenção viável possível. Esta etapa é a mais semelhante com o processo (5.3) Definir o escopo, sugerido pelo PMI (2013), tal como o resultado esperado se assemelhe ao documento (5.3.3.1) Especificação do Escopo do Projeto. A (5.3.2.3) Geração de Alternativas e (5.3.2.4) Oficinas Facilitadas são necessárias para a tomada das decisões. As fontes de informação devem ser as respostas do questionário da Crítica de Fronteira, da etapa anterior.

\section{CONSIDERAÇÕES FINAIS}

\subsection{CRÍTICAS E COMENTÁRIOS}

Através da aplicação da metodologia proposta, é possível compreender os benefícios que as Abordagens Sistêmicas podem incorporar à Gestão de Projetos. Sendo fundamentadas sobre o Pensamento Sistêmico, as abordagens levantam reflexões enriquecedoras para o desenvolvimento de soluções, uma vez que incentive a diversidade de perspectivas para a geração de ideias, e teste a validez destas através de questionamentos críticos.

Utilizadas de forma complementar às ferramentas propostas pelo PMI (2013), as Abordagens Sistêmicas reforçam as boas práticas ao diversificarem as análises, reduzindo os imprevistos, e flexibilizarem sua aplicação para diversos contextos, mantendo sua eficácia em situações onde aspectos externos (social, político ou cultural), não controláveis, potenciais imprevistos e variáveis subjetivas em geral, exerçam grande influência sobre o problema em questão.

O Pensamento Sistêmico agrega um valor diferenciado em relação ao PMI (2013) para a Definição do Escopo ao sugerir ferramentas como a Figura Rica, a Seleção de Perspectivas Chaves e Crítica de Fronteira. Seja combinando ferramentas já conhecidas, no caso da Figura Rica, ou oferecendo uma abordagem diferenciada, como as outras citadas, incluir a visão sistêmica para a solução de problemas servirá como complemento às boas práticas sugeridas pelo PMI (2013).

As ferramentas sistêmicas oferecem aos Gestores de Projeto uma oportunidade diferenciada de reflexão sobre o problema. Sua abordagem holística possui o diferencial de realizar avaliações considerando características subjetivas como valores éticos e morais, variáveis do contexto externo, atributos do relacionamento estre as partes, e seus pontos de vista sobre o problema de forma combinada. Isto permite o Gestor do Projeto a realizar análises mais ricas sobre as a situação, viabilizando o desenvolvimento de soluções mais efetivas. A adaptabilidade e abrangência que o Pensamento Sistêmico incorpora às boas 
práticas de Gestão de Projetos, flexibiliza sua aplicabilidade para diversos tipos de contexto, desde negócios até sociais, assim como pode dar usado em todas as etapas do projeto.

As boas práticas sugeridas pelo PMI (2013) são mundialmente famosas por disponibilizarem um amplo conhecimento de especialistas e capacitarem os Gestores de Projetos a desenvolverem, monitorarem e controlarem seus empreendimentos. Com o modelo proposto, identifica-se uma oportunidade de incremento às boas práticas ao incorporarem princípios oriundos do Pensamento Sistêmico em sua formulação, complementando a efetividade da sua aplicação.

\subsection{RECOMENDAÇões PARA TRABALHOS FUtUROS}

A principal afirmação deste trabalho é sugerir a utilização de abordagens sistêmicas como ferramenta complementar para o trabalho do Gestor de Projetos. No entanto, o estudo de caso se restringiu ao uso de uma metodologia específica, assim como focou no processo de definição de escopo de um projeto. Como sugestão de trabalho futuro, pode-se aplicar:

a) Outras ferramentas sistêmicas para a Definição de escopo, como a análise BATWOVE (MIDGLEY; Reynolds, 2001); adaptação do CATWOE (Checkland, 1981), Mapeamento Cognitivo / SODA (Eden, 1989), Análise Modelos Mentais (Senge, 2003), assim como a combinações destas.

b) Aplicação de abordagens sistêmicas em outros processos da Gestão de Projetos, principalmente os que requeiram análises sobre diversas variáveis, reflexões subjetivas e considerações contextuais, como nas áreas de Gerenciamento das Partes Interessadas, Gerenciamento dos Riscos ou Gerenciamento da Integração do Projeto.

c) Aplicar as sugestões anteriores em estudos de caso em contextos distintos, desde um projeto de implantação de governança corporativa até um projeto de melhoria de processos em um ONG, confirmando a vasta aplicação das boas práticas de Gestão de Projetos, assim como das Abordagens Sistêmicas, e os valores agregados pela combinação de ambos.

\section{REFERÊNCIAS}

[1] BEER, S. Brain of the Firm; Allen Lane, The Penguin Press, Londres, 1972.

[2] BERTALANFFY, Ludwig von. Teoria Geral dos Sistemas. São Paulo: Vozes, 1975.

[3] BIDER, I., BELLINGER, G., PERJONS, E.: Modeling an Agile Enterprise: Reconciling Systems and Process Thinking, LNBIP 92: 238-252, Springer, 2011.

[4] CABRERA, D; CABRERA, L. Systems Thinking Made Simple: New Hope for Solving Wicked Problems. Odyssean, 2015.

[5] CHECKLAND, P. Systems Thinking, Systems Practice. New York, John Willey \& Sons, 1981.

[6] _ Soft systems methodology: a thirty year retrospective, In: Systems Research and Behavioral Science Syst. Res., 2000.

[7] CHECKLAND, P.; SCHOLES Jim, Soft Systems Methodology in Action. Chichester, John Willey \& Sons, 1990.

[8] CHURCHMAN, C.W. Introdução à Teoria Geral dos Sistemas. 2. ed. São Paulo: Vozes, 1972.

[9] CONKLIN, J. E. Dialog Mapping: Building Shared Understanding of Wicked Problems, Napa, CA: CogNexus Institute, 2006.

[10] FLOOD, R. L.; JACKSON, M. C. Creative problem solving: Total systems intervention. Vol. 831397533. Chichester: Wiley, 1991.

[11] FORRESTER, J. W. Industrial dynamics. Boston: MIT Press, 1961.

[12] JACKSON, M. Systems methodology for the management sciences - Plenum Press, New York, 1991. 
[13] _ _ Systems Approaches to Management, Londres: Springer, 2000.

[14] MIDGLEY, G.; MUNLO, I.; BROWN M. The theory and practice of boundary critique: Developing housing services for older people. Journal of the Operational Research Society, 1988.

[15] MIDGLEY, G. What is this thing called CST? Critical Systems Thinking: Current Research and Practice (eds. R. Flood and M. Romm), pp. 1-24. New York: Plenum Press, 1996.

[16] _ An Introduction to Systems Thinking. Integration and Implementation Sciences (I2S), 2015.

[17] MIDGLEY, G.; M. REYNOLDS. Operational Research and Environmental Management: A New Agenda. Birmingham, Operational Research Society, 2001.

[18] PMI - PROJECT MANAGEMENT INSTITUTE, Inc. A guide to the Project management body of knowledge (PMBOK Guide). 5. ed. Pennsylvania, EUA, 2013.

[19] REYNOLDS, Martin. Bells that still can ring: systems thinking in practice. In: Tait, Andrew and Richardson, Kurt eds. Moving Forward with Complexity: Proceedings of the 1st International Workshop on Complex Systems Thinking and Real World Applications. Litchfield Park, AZ: Emergent Publications, pp. 327-349, 2011.

[20] RITTEL, H; WEBBER, M. Dilemmas in a General Theory of Planning Policy Sciences, Vol. 4, Elsevier Scientific Publishing Company, Inc., Amsterdam, 1973.

[21] ROSENHEAD, J. Rational Analyses for a Problemátic World: Problems Structuring Methods for Complexity, Uncertainty and Conflict. John Wiley \& Sons, Chinchester, 1989.

[22] SEnGE, P. M. A Quinta Disciplina: Arte e Prática da Organização de Aprendizagem. São Paulo: Editora Nova Cultural, 2003.

[23] ULRICH, W. Critical Heuristics of Social Planning: A New Approach to Practical Philosophy, Bern: Haupt., 1983.

[24] _ Critical heuristics of social planning: a new approach to practical philosophy. New York: Wiley, 1994.

[25] _ Boundary critique. In H.G. Daellenbach and R.L. Flood (eds.), The Informed Student Guide to Management Science, London: Thomson Learning, 2002.

[26] ULRICH, W.; REYNOLDS, M. Critical systems heuristics. In M. Reynolds, S. Sue (Eds.), Systems Approaches to Managing Change: A Practical Guide (pp. 243-292). London, England: Springer, 2010.

[27] WILLIAMS, Bob; HOF, Sjon Van’t. Wicked solutions: a systems approach to complex problems. Wellington, Nova Zelândia: Bob Williams, 2016. 